$\underline{\text { Araștırma Makalesi }}$

\title{
Farklı Gelişme Dönemlerinde Yaprak Hasadının Adaçayının (Salvia officinalis L.) Verim, Uçucu Yağ Oranı ve Kimyasal Kompozisyonuna Etkisi
}

ÖZ

\author{
Nimet KARA*
}

Araştırma, adaçayının (Salvia officinalis L.) çiçeklenme öncesi, tam çiçeklenme ve çiçeklenme sonrası dönemlerde yapılan hasatta yaprak (daldaki üst, orta ve alt yapraklar) ve çiçek verimi, uçucu yağ oranı ve kimyasal kompozisyonunun belirlenmesi amacıyla yürütülmüştür. Isparta Uygulamalı Bilimler Ünversitesi deneme alanında 2014 yılında kurulan 4 yaşındaki adaçayı plantasyonu materyal olarak kullanılmış ve çalışma 2018 yılında tesadüf bloklarında faktöryel deneme desenine göre 3 tekerrürlü planlanmıştır. En yüksek yaş ve kuru yaprak verimleri, çiçeklenme dönemi sonunda orta yaprakta (sırasıyla, $60.89 \mathrm{~g} / \mathrm{bitki} \mathrm{ve}$ $26.06 \mathrm{~g} / \mathrm{bitki})$ ve uçucu yağ oranı ise tam çiçeklenme döneminde üst yapraklarda (\%1.73) tespit edilmiştir. En düşük yaş ve kuru yaprak verimi çiçeklenme öncesi dönemde alt yapraklarda, uçucu yağ oranı ise çiçeklenme sonu alt yapraklarda belirlenmiştir. Yaş ve kuru çiçek verimi ve uçucu yağ oranı tam çiçeklenme döneminde çiçeklenme sonuna göre daha yüksek olmuştur. Adaçayının yaprak ve çiçeklerinin uçucu yağında 1,8 sineol, $\beta$-tuyon, $\alpha$-tuyon, kafur, borneol L, karyofillen, $\alpha$-humulen ve leden önemli bileşenler olarak belirlenmiştir. Genel olarak, çiçeklenem sonunda orta yaprakların yaş ve kuru yaprak verimi daha yüksek olmasına rağmen, uçucu yağın kalitesi bakımından; tüyon oranının yüksek, kafur oranının düşük olduğu çiçeklenme öncesi dönem olarak tespit edilmiştir. Yaprakların pozisyonları değerlendirdiğinde tüm gelişme dönemlerinde üst ve orta yaprakların alt yapraklara göre daha düşük oranda kafur içerdiği belirlenmiştir.

Anahtar Kelimeler: Salvia officinalis L., hasat dönemi, ucucu yağ bileşenleri, uçucu yağ oranı

\section{Effect on Yield, Essential Oil Content and Chemical Composition of Sage of Leaf Harvest to Different Growing Stages (Salvia officinalis L.)}

\begin{abstract}
Research was carred out with aim to determine of leaf (upper, middle and lower leaves on the branch) and flower yield, essential oil content and chemical composition in the harvest at before flowering, full blooming and after flowering stages of sage (Salvia officinalis L.). Sage plantation for four years that planted in 2014 in experiment field of the Isparta University of Applied Sciences was used as plant material, and the study was planned according to a randomized block design with factorial treatments with three replications in 2018 year. The highest fresh and dry leaf yields were determined in middle leaves at after flowering stage $(60.89 \mathrm{~g}$ plant $^{-1}$ and $26.06 \mathrm{~g} \mathrm{plant}^{-1}$, respectively), and the highest essential oil content $(1.73 \%)$ was obtained in upper leaves at full blomming stage. The lowest fresh and dry leaf yield were obtained in lower leaves at before flowering, while The lowest essential oil content was determined in lower leaves at after flowering stage. Fresh and dry flower yields and essential oil content at full bloming stage were higher than after flowering. $\beta$ thujone, 1,8-cineol, $\alpha$-thujone, camphor, borneol 1, caryophyllene, $\alpha$-humulene and ledene in the leaves and flowers of sage were determined as significant components. Generally, before flowering stage with high thujone and low camphor were determined in terms of the quality of essential oil, although, fresh and dry leaf yield were higher in the middle leaves at the end of flowering age. Evaluating the positions of leaves, camphor content of upper and middle leaves in all growing stages were lower according to lower leaves.
\end{abstract}

Keywords: Salvia officinalis L., harvest stage, essential oil components, essential oil content

ORCID ID (Yazar sırasına göre)

0000-0001-7069-0877

Yayın Kuruluna Geliş Tarihi: 15.10.2020

Kabul Tarihi: 21.12.2020

*Isparta Uygulamalı Bilimler Üniversitesi Ziraat Fakültesi Tarla Bitkileri Bölümü, Isparta

E-posta: nimetkara@isparta.edu.tr 


\section{Farklı Gelişme Dönemlerinde Yaprak Hasadının Adaçayının (Salvia officinalis L.) Verim, Uçucu Yağ Oranı ve Kimyasal Kompozisyonuna Etkisi}

\section{Giriş}

Günümüzde insanların sentetik ürünlerin yan etkilerinden dolayı bitkilerden elde edilen doğal ürünlere talep etmesi, tıbbi bitkilerin kullanım alanlarını ve üretimini arttırmıştır. Lamiaceae familyası üyeleri içerdikleri uçucu yağın koku ve tat verici özelliğinin yanısıra antibakteriyel ve antioksidan olmaları nedeniyle gida, kozmetik, parfümeri ve ilaç sanayi gibi pek çok alanda kullanılmaktadır. Lamiaceae familyasına bağlı olan Salvia cinsinin, Dünya'nın her iki yarım küresinde, özellikle tropik ve subtropik bölgelerle, Akdeniz ve Orta Avrupa' ya dağılmış 986' dan fazla türü bulunmaktadır (Karayel ve Akçura, 2016). Türkiye'de yetişen 97 türün 58 tanesi $(\% 59,7)$ 'si İran-Turan, 27 tanesi $(\% 27,8)$ Akdeniz, 5 tanesi (\%5) AvrupaSibirya fitocoğrafik bölgesinde, diğer kalan 7 tanesi de (\%7) birden fazla fitocoğrafik bölgede yayılış göstermektedir (Davis, 1982; Nakipoğlu, 1993; Seçmen ve ark., 2000; Doğan ve ark., 2008; İpek ve Gürbüz, 2010). Dünyada kültürü yapılan ve ticari değeri yüksek olan türü tıbbi adaçayı (Dalmaçya adaçayı) olarak da adlandırılan Salvia officinalis L. olup, diğer önemli adaçayı türleri $S$. fructicosa Mill., (syn. S. triloba L.) (Yunan veya Anadolu adaçayı), $S$. pomifera L. (elma adaçayı ), S. lavandulaefolia Vahl. (Ispanyol adaçay1) ve $S$. sclarea L. (misk adaçayı) dir (Baydar, 2019). Akdeniz ikliminin etkili olduğu bölgelerimizde "şalba" veya "çalba" olarak adlandırılan $S$. fructicosa ve $S$. tomentosa türleri ülkemizde doğal yayılış gösterirken, Salvia officinalis doğal olarak bulunmamakta ancak yetiştiriciliğ yapılmaktadır (Karakuş ve ark., 2017). Adaçayı uçucu yağında içerdiği tüyon, sineol ve kafur gibi bileşenlerin antimikrobial etkiye, karnosik asit, karnosol ve rosmarinik asit gibi fenoliklerden dolayıda antioksidan aktiviteye sahip olduğu tespit edilmiştir (Tuğlu ve Baydar, 2019). Uçucu yağ taşıyan bitkilerde, uçucu yağın kompozisyonu ve miktarı bitkinin cinsine, morfogenetiğine, üretim şekline, yetiştirildiği bölgenin coğrafi yapısına, iklime (Arraiza ve ark., 2012; Baydar, 2019, Lakusic ve ark., 2013) ve hatta yaprakların konumuna göre de farklılık gösterdiği yapılan çalışmalarla ortaya konulmuştur (Topuz ve Madanlar, 2006). İyi kalitede tıbbi adaçayında ISO (9909:1997) standartlarına göre $\alpha$-tüyon $\% 18-43, \beta$-tüyon \%3.0-8.5, kafur \%4.5-24.5 ve 1,8 sineol \%5.513.0 arasında olması gerekmektedir (Baydar, 2019). Araştırmada, adaçayının çiçeklenme öncesi, tam çiçeklenme ve çiçeklenme sonrasında dalda üst, orta ve alt yaprakların ve çiçeklerin yaş ve kuru verimi, uçucu yağ oranı ve kimyasal kompozisyonunun belirlenmesiyle en kaliteli yaprakların tespit edlmesi amacıyla yürütülmüştür.

\section{Materyal ve Yöntem}

Araştırmada, Isparta Uygulamalı Bilimler Üniversitesi araştırma alanında 2014 yılında 100 x $50 \mathrm{~cm}$ dikim siklığında kurulan 4 yaşındaki Salvia officinalis türü kullanılmıştır. Her parsel $4 \mathrm{~m}$ uzunluğunda 4 sira şeklinde tesadüf bloklarında faktöryel deneme desedine göre 3 tekerrürlü olarak 2018 yılında planlanmıştır. Deneme tarlası düzenli olarak yabanc1 otlardan temizlenmiş ve damlama boruları yardımıyla bitkinin ihtiyaç duyduğu zamanlarda sulama yapılmıştır. Adaçayında hasat; 2018 y1lında çiçeklenme öncesi (12 Mayıs 2018), tam çiçeklenme dönemi (22 Mayıs 2018) ve çiçeklenme sonrası (6 Temmuz 2018) olmak üzere üç dönemde bitkiler uçlardan $0.5 \mathrm{~m}$ ve diş sıralar kenar tesisi olarak atıldıktan sonra parsel alanı $\left(4 \mathrm{~m}^{2}\right) 15 \mathrm{~cm}$ yükseklikten kesilerek yapılmıştır. Langer ve ark. (1993) ve Lakusic ve ark. (2013)'e göre hasat sonrasında adaçayı dallarında üst (genç) yapraklar (bitkinin en üst 4 yaprağı), alt (yaşlı) yapraklar (bitkinin en alt 4 yaprağı), orta yapraklar (üst ve alt yapraklar alındiktan sonra kalan 3-4 yaprak) ve çiçek kısımları sap kısmından ayrılarak yaş ağırlıkları tartılmış ve kurutma raflarında kurutulmaya bırakılmıştır. Oda sıcaklığında gölge ve havadar bir ortamda 10 gün kurumaya bırakılan yaprak ve çiçeklerde kuru ağırlıkları tartılarak g/bitki hesaplanmıştır.

Verilerin alındığ 2018 Ocak-Temmuz aylarına ilişkin toplam yağış miktarı $351.7 \mathrm{~mm}$, uzun y1llar ortalamas1 ise $262.4 \mathrm{~mm}$ olarak gerçekleşmiştir. Aynı dönem içerisinde ortalama sicaklık $13.5{ }^{\circ} \mathrm{C}$ olup, uzun yillar sicaklık ortalamasından $\left(12.4{ }^{0} \mathrm{C}\right)$ yüksek olmuştur (Çizelge 1). 


\section{Farklı Gelişme Dönemlerinde Yaprak Hasadının Adaçayının (Salvia officinalis L.) Verim, Uçucu Yağ Oranı ve Kimyasal Kompozisyonuna Etkisi}

Çzelge 1. Deneme yılına ve uzun yıllara ait iklim verileri*

\begin{tabular}{llllllllll}
\hline & Y1llar & Ocak & SSubat & Mart & Nisan & Mayıs & Haziran & Temmuz & Ort./Top \\
\hline Sıcaklık & $2017 / 18$ & 3.1 & 6.3 & 9.2 & 14.8 & 16.8 & 20.3 & 24.3 & 13.5 \\
$\left({ }^{\circ} \mathrm{C}\right)$ & Uzun yıllar & 2.5 & 5.1 & 9.3 & 10.8 & 15.6 & 20.1 & 23.4 & 12.4 \\
\hline Yağış & $2017 / 18$ & 75.7 & 75.0 & 65.9 & 51.0 & 43.3 & 36.8 & 4.0 & 351.7 \\
$(\mathrm{~mm})$ & Uzun y1llar & 46.9 & 28.0 & 42.9 & 56.6 & 50.8 & 24.4 & 12.8 & 262.4 \\
\hline
\end{tabular}

*Isparta Meteoroloji İstasyonu iklim verileri

Deneme alanı toprağının $0-30 \mathrm{~cm}$ derinliği alınan toprak örneği; kumlu-tınlı bir yapıya sahip olup, bazik (pH: 8.22), kireç oranı yüksek (\%16.35) ve organik madde oranı (\%1.53) düşük yapıdadır.

\section{Uçucu yağ oranı ve bileşenleri}

Hasat sonrasında kurutulan adaçayı yaprak ve çiçeklerinde uçucu yağ oranı Tarla Bitkileri Bölümü labaratuvarında Clevenger tipi hidrodistilasyon cihazında 30 gr numune üzerine 500 $\mathrm{ml}$ su eklenerek 2 saat süre ile su distilasyonu yöntemiyle belirlenmiştir. Distilasyon sonrasında ölçülü bölümde toplanan yağ miktarı ölçülerek \% uçucu yağ oranı hesaplanmıştır. Her bir adaçayı uçucu yağ örneğinin uçucu yağ bileşenleri GC/MS (Gas chromatography/Mass spectrometry) cihazında (QP-5050 quadrapole detektörlü Shimadzu 2010 Plus) CP-Wax 52 CB $(50 \mathrm{~m}$ x $0.32 \mathrm{~mm} .0 .25 \mu \mathrm{m})$ kapiler kalonu kullanılarak belirlenmiştir. Analizlerde firın sıcaklık programı dakikada $10{ }^{\circ} \mathrm{C}$ artarak 60 ${ }^{\circ} \mathrm{C}$ 'den $220^{\circ} \mathrm{C}$ 'ye ulaşmıș ve $220{ }^{\circ} \mathrm{C}$ 'de 10 dakika kadar bekletilmiştir. Toplam koşturma süresi 60 dakika, enjektör sicaklığ $240{ }^{\circ} \mathrm{C}$ ve detektör sıcaklığ $1250{ }^{\circ} \mathrm{C}$ olarak ayarlanmıştır. Taşıyıcı gaz olarak helyum gazı $(20 \mathrm{~mL} /$ dakika, split 1:20) kullanılmıştır.

Elde edilen verilerin istatistik analizleri, SAS paket programı kullanılarak yapılmış ve ortalamalar arasindaki farklar DUNCAN testine göre belirlenmiştir.

\section{Bulgular ve Tartışma \\ Taze ve kuru yaprak verimi}

Adaçayında farklı hasat dönemlerinde dalda üst, orta ve alt yaprakların taze ve kuru yaprak verimi Çizelge 2'de verilmiştir. Hasat dönemi, yaprak pozisyonu ve dönem $x$ yaprak pozisyonu interaksiyonu istatistiksel olarak önemli olmuştur. Toplam taze ve kuru yaprak verimleri çiçeklenme öncesi dönemden, çiçeklenme sonuna doğru bitki gelişimine ve iklime (sıcaklıkların artması) bağlı olarak artış göstermiş ve en yüksek çiçeklenme sonunda ( $165.57 \mathrm{~g} / \mathrm{bitki}$ ve $64.36 \mathrm{~g} / \mathrm{bitki}$ ) elde edilmiştir. En düşük ise çiçeklenme öncesi dönemde (67.66 g/bitki ve $17.59 \mathrm{~g} / \mathrm{bitki})$ belirlenmiştir (Çizelge 2). Yaprak pozisyonları incelendiğinde, taze ve kuru yaprak verimleri üst yapraklardan (üst yapraklarda; sirasılyla 43.25 ve $14.58 \mathrm{~g} / \mathrm{bitki}$, orta yapraklarda; 37.85 ve $12.63 \mathrm{~g} / \mathrm{bitki}$ ve alt yapraklarda; 34.35 ve $11.07 \mathrm{~g} / \mathrm{bitki}$ ) alt yapraklara doğru azalmıştır (Çizelge 2). Şenkal ve ark. (2012) Salvia officinalis'te en yüksek yaş ve kuru yaprak veriminin tam çiçeklenme döneminde daha yüksek elde edildiğini, Baranauskiene (2011) adaçayında taze herba verimine en yüksek çiçeklenme döneminde ulaştığını ve çiçeklenme sonras1 tohum olgunlaşma döneminde azaldığını bildirmişlerdir. Bağdat ve ark. (2017) Salvia officinalis'in kuru yaprak veriminin 16.1-74.5 g/bitki arasında değiştiğini, Karaaslan ve Özgüven (1998) yaş yaprak veriminin $2992 \mathrm{~kg} / \mathrm{da}$, kuru yaprak veriminin $748.6 \mathrm{~kg} / \mathrm{da}$ olduğunu bildirmişlerdir. Tıbbi adaçayında yapılan araştırmalarda verimdeki değişikliklerin ekoloji, materyal, yetiştiricilikteki uygulama farklılı̆̆ (Koç, 2000), fizyolojik dönem ve çok yıllık bitki olmasi dolayısıyla bitkinin yaşından kaynaklandığı düşünülmektedir.

\section{Yaprak uçucu yağ oranı}

Adaçayının çiçeklenme öncesi, tam çiçeklenme ve çiçeklenme sonu dönemlerinde yaprak uçucu yağ oranları arasındaki fark istatistiksel olarak önemli bulunmuştur (Çizelge 2). Adaçayının hasat dönemleri ve yaprak pozisyonlarına göre uçucu yă̆ oranları \%0.60-1.73 arasında değișiklik göstermiș ve en yüksek tüm biçim dönemlerinde üst ve orta yapraklarda belirlenmiştir. Salvia officinalis' in kuru yaprak 


\section{Farklı Gelişme Dönemlerinde Yaprak Hasadının Adaçayının (Salvia officinalis L.) Verim, Uçucu Yağ Oranı ve Kimyasal Kompozisyonuna Etkisi}

uçucu yağ oranının Ekren ve ark. (2007) \%1.50, Porte ve ark. (2013) \%2.3, Rezaeieh ve Gurbüz

(2017) \%1.67 oranında araştırma bulgularımızla paralel olarak tespit etmişledir.

Çizelge 2. Farklı hasat dönemlerinde adaçayının yaprak pozisyonlarına göre yaprak verimi ve uçucu yağ oranı

\begin{tabular}{|c|c|c|c|c|}
\hline \multirow{3}{*}{ Hasat dönemleri } & \multicolumn{4}{|c|}{ Taze yaprak verimi (g/bitki) } \\
\hline & \multicolumn{4}{|c|}{ Yaprak pozisyonu } \\
\hline & Üst yaprak & Orta yaprak & Alt yaprak & Toplam yaprak verimi \\
\hline Çiçeklenme Öncesi & $21.85 \mathrm{e}$ & $24.29 \mathrm{e}$ & $21.52 \mathrm{e}$ & $67.66 \mathrm{C}$ \\
\hline Tam Çiçeklenme & $47.01 \mathrm{c}$ & $32.75 \mathrm{~d}$ & $33.30 \mathrm{~d}$ & $113.09 \mathrm{~B}$ \\
\hline Çiçeklenme Sonu & $60.89 \mathrm{a}$ & $56.49 \mathrm{~b}$ & $48.19 \mathrm{c}$ & $165.57 \mathrm{~A}$ \\
\hline Ortalama & $43.25 \mathrm{~A}$ & $37.85 \mathrm{~B}$ & $34.35 \mathrm{C}$ & \\
\hline \multicolumn{5}{|c|}{ F değeri, Hasat dönemi: 430.206**, Yaprak pozisyou: $7.17^{*}$, HD xYP: $42.44^{* *}$, VK $(\%): 7.47$} \\
\hline \multirow{3}{*}{ Hasat dönemleri } & \multicolumn{4}{|c|}{ Kuru yaprak verimi (g/bitki) } \\
\hline & \multicolumn{3}{|c|}{ Yaprak pozisyonu } & \\
\hline & Üst yaprak & Orta yaprak & Alt yaprak & Toplam yaprak verimi \\
\hline Çiçeklenme Öncesi & $6.28 \mathrm{~d}$ & $6.64 \mathrm{~d}$ & $4.67 \mathrm{~d}$ & $17.59 \mathrm{C}$ \\
\hline Tam Çiçeklenme & $11.41 \mathrm{c}$ & $10.56 \mathrm{c}$ & $10.94 \mathrm{c}$ & $32.91 \mathrm{~B}$ \\
\hline Çiçeklenme Sonu & $26.06 \mathrm{a}$ & $20.70 \mathrm{~b}$ & $17.60 \mathrm{~b}$ & $64.36 \mathrm{~A}$ \\
\hline Ortalama & $14.58 \mathrm{~A}$ & $12.63 \mathrm{~B}$ & $11.07 \mathrm{C}$ & \\
\hline \multicolumn{5}{|c|}{ F değeri, Hasat dönemi: 445.74**, Yaprak pozisyou: 6.76*, HD xYP: 58.26**, VK (\%): 10.34} \\
\hline \multirow{3}{*}{ Hasat dönemleri } & \multicolumn{4}{|c|}{ Kuru yaprak uçucu yağ oranı (\%) } \\
\hline & \multicolumn{3}{|c|}{ Yaprak pozisyonu } & \\
\hline & Üst yaprak & Orta yaprak & Alt yaprak & Ortalama \\
\hline Çiçeklenme Öncesi & $1.63 \mathrm{a}$ & $1.30 \mathrm{~b}$ & $0.76 \mathrm{~d}$ & $1.23 \mathrm{~B}$ \\
\hline Tam Çiçeklenme & $1.73 \mathrm{a}$ & $1.62 \mathrm{a}$ & $0.73 \mathrm{~d}$ & $1.36 \mathrm{~A}$ \\
\hline Çiçeklenme Sonu & $1.26 \mathrm{~b}$ & $1.20 \mathrm{c}$ & $0.60 \mathrm{c}$ & $1.02 \mathrm{C}$ \\
\hline Ortalama & $1.54 \mathrm{~A}$ & $1.37 \mathrm{~B}$ & $0.69 \mathrm{C}$ & \\
\hline
\end{tabular}

\section{Taze ve kuru çiçek verimi}

Adaçayı çiçeklerinin tam çiçeklenme ve çiçeklenme sonu dönemlerinde taze ve kuru çiçek verimi değişiklik göstermiş ve istatistiksel olarak önemli bulunmuştur (Şekil 1). En yüksek taze çiçek (104.45 g/bitki) ve kuru çiçek verimi $(25.59 \mathrm{~g} / \mathrm{bitki})$ tam çiçeklenme döneminde elde edilmiştir. Çiçeklenme sonunda sıcaklıkların etkisiyle adaçayı çiçeklerinin nem kaybetmesi ve kurumalardan dolayı çiçek dökülmeleri meydana gelmiş ve verimde azalma olmuştur. Yılmaz (1988) yaş çiçek veriminin 661.1-853.5 $\mathrm{kg} / \mathrm{da}$, drog çiçek veriminin $177.0-298.3 \mathrm{~kg} / \mathrm{da}$, Yenikalaycı (1998) yaş çiçek veriminin 216.5-
$432.1 \mathrm{~kg} / \mathrm{da}$, drog çiçek veriminin 50.7-95.7 $\mathrm{kg} / \mathrm{da}$ arasında değiştiğini bildirmişlerdir.

\section{Çiçekte uçucu yağ oranı}

Hasat dönemlerine göre adaçayı çiçeklerinin uçucu yağ oranı değişiklik göstermiş ve tam çiçeklenme döneminde uçucu yağ oranı (\%1.46), çiçeklenme sonu döneminden $(\% 0.83)$ daha yüksek olmuştur (Şekil 1). Karayel (2019) adaçayında uçucu yağ oranı drog çiçekte $\% 1,32-\% 2,33$, Couladis ve ark. (2002) \%0741.31, Y1lmaz (1988) \% 0.50-0.58, Yenikalayc1 (1998) \%0.73-2.11 ile araştıma bulgularımızla benzerlik göstermektedir. 


\section{Farkı Gelişme Dönemlerinde Yaprak Hasadının Adaçayının (Salvia officinalis L.) Verim, Uçucu Yağ Oranı ve Kimyasal Kompozisyonuna Etkisi}
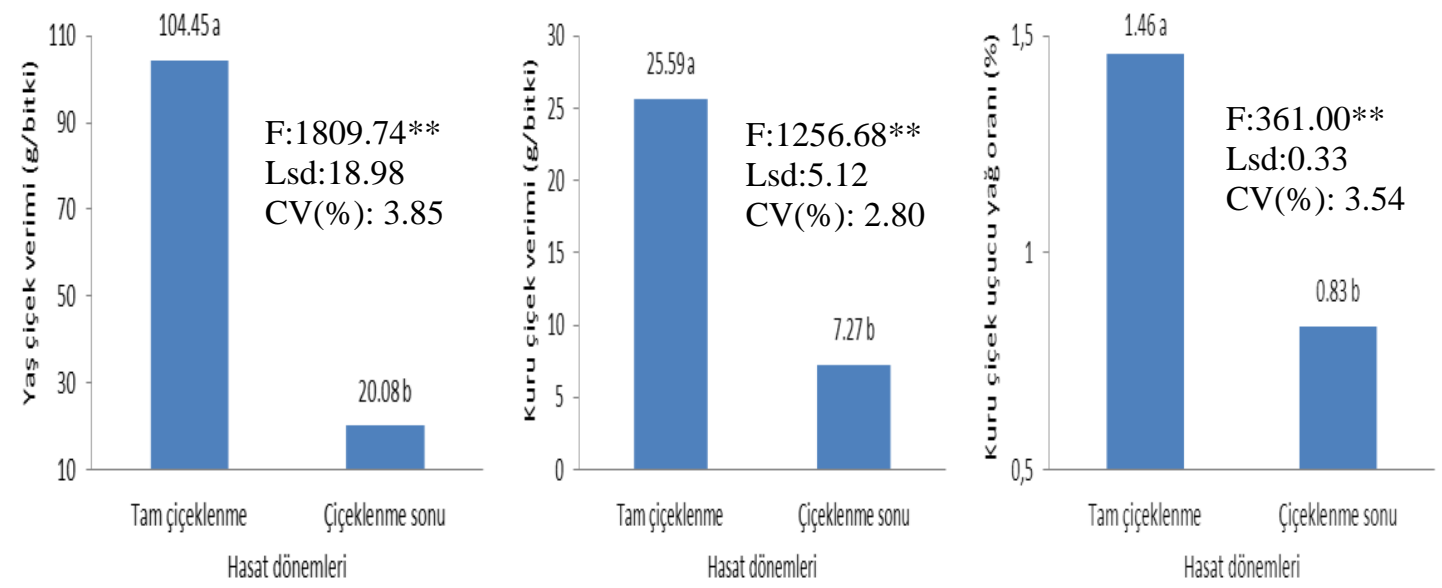

Şekil 1. Adaçayının farklı hasat dönemlerinde çiçek verim ve uçucu yağ oranı

Adaçayı Yaprak ve Çiçeklerinde Uçucu Yağ Bileşenleri

Adaçayının çiçeklenme öncesi, tam çiçeklenme ve çiçeklenme sonu dönemlerinde üst, orta ve alt yapraklarında toplam 41 adet uçucu yağ bileşeni tespit edilmiş ve ana bileşenler olarak 1,8 sineol, $\beta$-tüyon, $\alpha$-tüyon, kafur, borneol $\mathrm{L}$, karyofillen, $\alpha$-humulen ve leden belirlenmiştir (Çizelge 3).

Adaçayının çiçeklenme öncesi, çiçeklenme dönemi ve çiçeklenme sonrası dönemlerde $\alpha$ tüyon sirasiyla \%29.42-30.81, \%6.80-7.04, $\% 9.29-10.94, \quad \beta$-tüyon \%1.45-2.52, \%12.2418.67, \%23.78-27.67, kafur \%1.492.24,\%11.81-19.16, \%19.34-21.66, 1,8 sineol \%13.14-20.41, \%24.65-30.19, \% 12.72-13.42, , karyofillen \%1.17-1.60, \%4.34-9.92, \%2.703.39, $\alpha$-humulen \%12.84-17.95, \%1.77-4.25, \%3.61-4.46, borneol L \%6.95-8.83, \%1.65$2.50, \% 0.0-1.48$ ve leden $\% 7.19-12.68,4.20$ 6.05, \% 4.86-6.42 arasında değişmiştir (Çizelge $3)$. Adaçayı yapraklarında $\alpha$-tüyon, $\alpha$-humulen, borneol $\mathrm{L}$ ve leden bileşenin çiçeklenme öncesi dönemde, 1,8 sineol ve karyofillen çiçeklenme döneminde, $\beta$-tüyon ve kafur bileşeni ise çiçeklenme sonrası dönemde daha yüksek değerler göstermiştir. Özellikle $\alpha$-tüyon oranının en yüksek ve kafur oranının en düşük olduğu dönem çiçeklenme öncesi dönem olarak tespit edilmiştir. Adaçayında daha önce dönemsel olarak yapılan çalışmalarda benzer olarak, Arraiza ve ark. (2012) adaçayında uçucu yağdaki ana bileşen oranının tüm fenolojik dönemlerde değiştiğini, $\alpha$-pinen, $\alpha$-tüyon, $\beta$ - tüyon,borneol ve viridiflorol'un ilk çiçeklenme döneminde, sineol ve ve kafurun tam çiçeklenme sonrası dönemde daha yüksek değere sahip olduğunu bildirmişlerdir. Başyiğit ve Baydar (2017) farklı zamanlarda hasat yapılan adaçayında 1,8 sineol ve kafur oranlarının ilkbahar aylarında daha düşük oranlarda, $\alpha$ ve $\beta$-tüyon oranlarının ise ilkbahar aylarında daha yüksek oranlarda bulunduğu tespit edilmişlerdir.

Adaçayının üst, orta ve alt yaprakların tüyon oranları birbirlerine yakın olurken, kafur oran1 çiçeklenme öncesinden çiçeklenme sonuna doğru artış göstermiştir. Alt yaprakların kafur oran1 (\%19.16), üst ve orta yapraklara göre (\%11.81 ve \%12.53) oldukça yüksek olmuştur. Diğer kimyasal bileşenler hasat dönemine göre farklılıklar göstermiş ancak üst, orta ve alt yapraklardaki oranları yakın olmuştur.

Araştırmamıza paralel olarak, Langer ve ark. (1993) adaçayında üst yapraklardan alt yapraklara doğru $\alpha$-tüyon oranının azalırken, kafur, $\alpha$-pinen ve kampen oranının arttığını bildirmişlerdir. Santos-Gomes ve FernandesFerreira (2001) adaçayı esansiyel yağının bileşiminde hasat zamanında baskın organların doku tipi ve yaşının belirleyici olduğunu bildirmişlerdir.

Adaçayı çiçeklerinin uçucu yağında toplam 26 adet bileşen tespit edilmiş, $\alpha$ ve $\beta$-tüyon, kafur ve borneol $\mathrm{L}$ oranı çiçeklenme sonrasında daha yüksek olurken (sirasiyla \%16.95, \%36.18, \%18.04, \%5.62), 1,8 sineol çiçeklenme döneminde (\%38.9) daha yüksek olduğu 


\section{Farklı Gelişme Dönemlerinde Yaprak Hasadının Adaçayının (Salvia officinalis L.) Verim, Uçucu Yağ Oranı ve Kimyasal Kompozisyonuna Etkisi}

belirlenmiştir. Karyofillen, $\alpha$-humulen ve leden bileşenleri çiçeklenme döneminde tespit edilirken çiçeklenme sonrasında belirlenememiştir. Adaçayı çiçeklerinde, Karayel (2019) birinci biçimde $\alpha$-tüyon $\% 26,56, \quad 1,8$-sineol $\% 14,01$, viridiflorol
$\% 14,67$; ikinci biçim ise $\alpha$-tüyon \%39,51, kafur $\% 20,22$, 1,8-sineol \%10,27 bulunmuștur. Santos-Gomes ve Fernandes-Ferreira (2001), tüyon $\% 17.7,1,8$-sineol $\% 17.3$ ve $\beta$-pinen $\% 17.0$ ana bileșen olarak tespit etmişlerdir.

Çizelge 3. Farklı hasat dönemlerinde adaçayı yaprak ve çiçeklerinde uçucu yağ bileşen ve oranları

\begin{tabular}{|c|c|c|c|c|c|c|c|c|c|c|c|c|}
\hline \multirow{2}{*}{$\begin{array}{l}\text { Uçucu Yağ } \\
\text { Bileşenleri }\end{array}$} & & \multicolumn{3}{|c|}{ Çiçeklenme öncesi } & \multicolumn{4}{|c|}{ Çiçeklenme Dönemi } & \multicolumn{4}{|c|}{ Çiçeklenme Sonrası } \\
\hline & RT & Ü.Y & $\mathrm{O} . \mathrm{Y}$ & A.Y & Ü.Y & O.Y & A.Y & Çiçek & Ü.Y & $\mathrm{O} . \mathrm{Y}$ & A.Y & Çiçek \\
\hline$\alpha$-pinene & 6.51 & 2.12 & 0.77 & 1.62 & 1.93 & 2.46 & 1.90 & 3.17 & 1.33 & 1.55 & 1.39 & 1.07 \\
\hline $\mathrm{Cam}$ & 7.07 & 1.43 & 0.58 & 1.09 & 1.96 & 2.88 & 3.42 & 1.59 & 2.64 & 2.58 & 2.25 & 0.78 \\
\hline$\beta$-Phellandrene & 7.89 & 0.17 & 0.08 & 0.09 & 0.11 & 0.14 & 0.09 & 0.25 & 0.08 & 0.08 & 0.07 & - \\
\hline $1-\beta$-pinene & 8.09 & 3.52 & 1.77 & 3.01 & 4.38 & 4.75 & 3.45 & 13.3 & 2.89 & 2.87 & 2.41 & 4.20 \\
\hline 3-Octanone (CAS) & 8.34 & - & - & - & 0.02 & 0.02 & 0.06 & - & & - & - & - \\
\hline$\beta$-my & 8.53 & 1.06 & 0.54 & 0.53 & 2.83 & 3.37 & 1.69 & 1.20 & 1.31 & 1.21 & 1.09 & 0.77 \\
\hline ndrene & 9.25 & 0.02 & - & 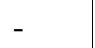 & . & 0.02 & 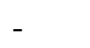 & 0.02 & 0.05 & 0.05 & 0.04 & - \\
\hline 1-methyl-4 & 9.73 & 0.13 & 0.16 & 0.06 & 0.05 & 0.24 & 0.05 & 0.24 & & - & - & - \\
\hline Benzen methyl & 10.09 & 0.17 & 0.17 & 0.27 & 0.20 & 0.27 & 0.53 & 0.20 & 0.42 & 0.37 & 0.42 & - \\
\hline Lims & 10.31 & 0.91 & 0.56 & 0.59 & . & - & 1.43 & 0.64 & 1.89 & 1.76 & 1.66 & 1.26 \\
\hline Born & 10.33 & - & - & & 1.14 & 1.14 & - & - & & - & - & . \\
\hline $1,8-$ & 10.52 & 20.41 & 13.14 & 14.75 & 30.19 & 30.14 & 24.65 & 38.9 & 12.7 & 13.4 & 213.0 & 10.1 \\
\hline cis- $\mathrm{O}$ & 10.63 & 0.76 & 0.52 & 0.50 & 0.53 & 0.55 & 0.21 & 0.18 & 0.13 & 0.22 & 0.21 & - \\
\hline$\beta$-Oci & 11.15 & 0.19 & 0.12 & 0.14 & 0.11 & 0.12 & 0.03 & 0.02 & 0.03 & 0.04 & 0.04 & - \\
\hline$\gamma-\mathrm{Te}$ & .73 & 0.42 & 0.27 & 0.28 & 0.32 & 0.32 & 0.19 & 0,37 & & 0.40 & 0.39 & 0.50 \\
\hline abinen & 12.35 & 0.29 & 0.32 & 0.30 & 0.67 & 0.35 & 0.97 & 1.08 & 0.33 & 0.79 & 0.78 & - \\
\hline$\alpha$-ter & 13.16 & 0.17 & - & - & 0.13 & - & 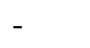 & - & 0.36 & 0.03 & 50.47 & - \\
\hline Lina & 14.02 & 0.97 & 1.16 & 1.15 & - & - & . & - & & - & - & - \\
\hline$\beta$-th & 14.37 & 2.52 & 1.45 & - & 12.45 & 12.24 & 18.67 & 6.42 & 27.6 & 23.7 & 325.4 & 36.1 \\
\hline$\alpha$-th & 15.00 & 29.42 & 30.81 & 29.47 & 6.80 & 6.80 & 7.04 & 3.32 & 10.9 & 10.7 & 59.29 & 16.95 \\
\hline $2,4,6$ & 15.62 & 0.16 & 0.10 & 0.08 & 0.12 & 0.12 & - & - & 0.02 & & - & - \\
\hline Thu & 21 & - & 0.22 & - & - & - & 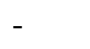 & - & 0.56 & 0.35 & 0.61 & 0.64 \\
\hline Cam & 16.68 & 1.71 & 1.49 & 2.24 & 11.81 & 12.53 & 19.16 & 5.47 & 19.3 & 21.6 & 622.5 & 18.04 \\
\hline $3-\mathrm{Pi}$ & 17.43 & - & - & - & 0.41 & 0.40 & 0.41 & - & 0.04 & - & - & - \\
\hline Borl & 18.18 & - & 8.83 & 6.95 & 1.65 & 1.74 & 2.50 & 2.25 & & - & 1.48 & 5.62 \\
\hline $4-\mathrm{T}$ & 18.72 & 0.16 & - & 0.22 & 0.29 & 0.23 & - & - & 0.21 & 0.21 & 0.22 & 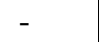 \\
\hline$\beta-\mathrm{fe}$ & 19.66 & 0.18 & 0.19 & 0.24 & 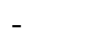 & - & - & 0.11 & 0.25 & 0.30 & 0.25 & - \\
\hline Myr & 9.72 & - & - & 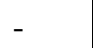 & 0.11 & 0.09 & 0.32 & - & -- & - & - & - \\
\hline Cis 3 & 22.40 & 0.04 & 0.11 & 0.08 & . & - & - & - & 1 & - & - & - \\
\hline Bor & 25.41 & 1.52 & 2.80 & 1.64 & 1.21 & 0.88 & - & - & 1.04 & 0.88 & 0.89 & - \\
\hline$\alpha-Y$ & 38.64 & 0.09 & 0.02 & 0.06 & - & 0.02 & - & - & & - & - & - \\
\hline Bou & 31.73 & 0.06 & 0.09 & 0.10 & - & 0.04 & - & - & 0.08 & 0.08 & 0.04 & - \\
\hline Car & 34.02 & 1.17 & 1.60 & 1.30 & 9.92 & 5.49 & 4.32 & 12.3 & 2.70 & 3.39 & 3.30 & - \\
\hline & 36.27 & 12.84 & 17.95 & 15.14 & 3.58 & 4.25 & 1.77 & 1.54 & 3.61 & 4.30 & 4.46 & - \\
\hline Allo & 36.51 & 0.11 & 0.14 & 0.12 & 0.04 & 0.03 & - & 0.09 & 0.10 & 0.05 & - & - \\
\hline$\alpha$-am & 37.57 & - & 0.50 & 0.35 & - & 0.08 & - & - & 0.02 & - & - & 0.80 \\
\hline Cadi & 39.93 & 0.06 & 0.15 & 0.11 & - & - & - & - & 0.02 & - & - & - \\
\hline$\Delta$-ca & 40.30 & 0.22 & 0.49 & 0.38 & 0.04 & 0.08 & - & 0.05 & - & 0.05 & - & 1.10 \\
\hline Cary & 43.94 & 0.45 & 1.30 & 1.64 & 0.81 & 1.29 & 1.35 & 0.30 & 0.90 & 0.94 & 1.40 & - \\
\hline & 44.78 & 7.19 & 10.67 & 12.68 & 5.90 & 6.05 & 4.20 & 6.56 & 6.32 & 4.86 & 6.42 & 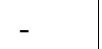 \\
\hline$\beta$-Selinene & 44.98 & - & 0.22 & 0.34 & - & 0.12 & - & - & 0.17 & 0.14 & 0.19 & - \\
\hline
\end{tabular}

Ü.Y: Üst yaprak, O.Y: Orta yaprak, A.Y: Alt yaprak 


\section{Farklı Gelişme Dönemlerinde Yaprak Hasadının Adaçayının (Salvia officinalis L.) Verim, Uçucu Yağ Oranı ve Kimyasal Kompozisyonuna Etkisi}

Salvia officinalis L.'de uçucu yă̆ kompozisyonun Arraiza ark. (2012) mevsime, Zutic ve ark. (2003) bitkinin gelişme evresinden daha çok, ekolojik koşullara, hasat dönemi ve bitki kısımlarına, Lakusic ve ark. (2013) yaprak gelişiminin ontogenetik evresine (genç ve yaşl1) bağlı olduğu kadar aynı zamanda genetik yapısına bağlı olduğunu bildirmişlerdir.

\section{Sonuc}

Adaçayında, en yüksek taze ve kuru yaprak verimi çiçeklenme sonrası dönemde ve üst yapraklardan elde edilmiştir. Adaçayında kalite kriteri olarak özellikle tüyon oranları yüksek ve kafur oranı düşük çeşitler ticari değer taşımaktadır. Bu nedenle uçucu yağın kalitesi bakımından özellikle tüyon oranının yüksek ve kafur oranının düşük olduğu en uygun dönem çiçeklenme öncesi olarak tespit edilmiştir. Yaprak pozisyonları bakımında tüm hasat dönemlerinde üst ve orta yaprakların alt yapraklara göre daha düşük miktarda kafur içerdiğinden dolayı özellikle genç yaprakların daha kaliteli olduğu düşünülmektedir. Üretim amacına göre, daha kaliteli ürün hedefi için çiçeklenme öncesi dönemde üst ve orta yaprakların hasat edilmesi, daha yüksek uçucu yağ oranı için ise tam çiçeklenme zamanında hasat yapılabileceği tespit edilmiştir. Verim kaybını önlemek için alt yaprakların hasat edilip ayrı bir şekilde değerlendirilebilir.

\section{Kaynaklar}

Arraiza, M.P., Arrabal, C., Lopez, J.V. (2012). Seasonal variation of essential oil yield and composition of sage (Salvia officinalis L.) grown in castilla-La Mancha (Central Spain). Notulae Botanicae Horti Agrobotanici 40: 106108.

Bağdat, R.B., Çinkaya, N., Demiray, K.Y., Bozdemir, C.., Çakır, E. (2017). Common sage (Salvia officinalis L.) breeding studies in Central Anatolian climatic conditions. Inter $J$ of Secondary Metabolite 4: 499-507.

Başyiğit, M., Baydar, H. (2017). Tıbbi adaçayı (Salvia officinalis L.)'nda farklı hasat zamanlarının uçucu yağ ve fenolik bileșikler ile antioksidan aktivite üzerine etkisi. Süleyman Demirel Üni, Fen Bilimleri Enst Der 21: 131-137.

Baranauskiene, R., Dambrauskiene, E., Venskutonis, P.R., Viskelis, P. (2011). Influence of harvesting time on the yield and chemical composition of sage (Salvia officinalis L.). Foodbalt Proceedings, https://llufb.llu.lv/conference/foodbalt/20 11/FOODBALT-Proceedings-2011-104109.pdf.

Baydar, H. (2019). Tibbi ve Aromatik Bitkiler Bilimi ve Teknolojisi (Genişletilmiş 6 . Bask1). Nobel Yayın No: 2328 (ISBN: 978-605-7846-38-9).

Couladis, M., Tzakou, O., Mimica-Dukic, N., Jancic, R. and Stojanovic, D. (2002). Essential oil of Salvia officinalis L. from Serbia and Montenegro. Flavour and Fragrance J 17: 119-126.

Davis, P.H. (1982). Flora of Turkey and The East Aegeans Islands. Vol: 1-11 The University Press. Edinburg, İngiltere.

Doğan M., Pehlivan, S., Akaydın, G., Bağcı, E., Uysal, İ., Doğan, H.M. (2008). Türkiye'de yayılıș gösteren Salvia L. (Labiatae) cinsinin taxonomik revizyonu. Tübitak Proje No: 104T450.

Ekren, S., Sönmez, Ç., Sancaktaroğlu, S., Bayram, E. (2007). Farklı biçim yüksekliklerinin adaçayı (Salvia officinalis L.) genotiplerinde agronomik ve teknolojik özelliklere etkisinin belirlenmesi. Ege Üni Ziraat Fak Der 44: 55-70.

İpek, A., Gürbüz, B. (2010). Türkiye florasında bulunan Salvia türleri ve tehlike durumları. Tarla Bitkileri Merkez Araş Enstitüsü Der 19(1-2): 30-35.

Karaaslan, D., Özgüven, M. (1998). Farklı azot dozlarının tıbbi adaçayı (Salvia officinalis L.)'nın verim ve yağ kalitesi üzerine etkisi. Cukurova Üniv Ziraat Fak Der 13: 185-194.

Karakuş, M., Baydar, H., Erbaş, S. (2017). Tıbbi adaçayı (Salvia officinalis L.) populasyonundan geliştirilen klonların verim ve uçucu yağ özellikleri. Tarla Bitkileri Merkez Araş Enst Der 26 (Özel Say1): 99-104. 


\section{Farklı Gelişme Dönemlerinde Yaprak Hasadının Adaçayının (Salvia officinalis L.) Verim, Uçucu Yağ Oranı ve Kimyasal Kompozisyonuna Etkisi}

Karayel, H.B., Akçura, M. (2016). Farklı lokasyonlarda yetiştirilen anadolu adaçayı (Salvia fruticosa Mill.)'in uçucu yă bileşenlerindeki değişimlerin incelenmesi. Gaziosmanpaşa Bilim Araş Der 13: 13-23.

Karayel, H.B. (2019). Kütahya (Çavdarhisar) yöresinde yetiştirilen tıbbi adaçayı (Salvia officinalis $\quad$ L.) türünün çiçeklerindeki uçucu yağ bileşenlerinin değerlendirilmesi. Avrupa Bilim ve Teknoloji Der 16: 528-532.

Koç, H. (2000). Tıbbi adaçayı (Salvia officinalis L.) azotlu gübrelemenin verim ve kalite üzerine etkisi. Gaziosmanpaşa Üniv Ziraat Fak Der 17: 89-93.

Lakusic, S.B., Ristic, S.M., Slavkoska, N.V., Stojanovic, L.J. Lakusic, D. (2013). Variations of essential oil yields and compositions of Salvia officinalis (Lamiaceae) at different development stages. Institute of Botany and Botanical Gargen Jevremovac 37: 127-139.

Langer, R., Mechtler, Ch., Tanzler, H. O., Jurenitsch, J. (1993). Differences of the composition of the essential oil within an individuum of Salvia officinalis. Planta Medica 59: A635-636.

Nakipoğlu M. (1993). Türkiye'nin Salvia L. türleri üzerinde karyolojik araştırmalar I. Türk Botanik Der 17(1): 21-258.

Porte, A., Godoy, R.L.O., Maia-Porte, L.H. (2013). Chemical composition of sage (Salvia officinalis L.) essential oil from the Rio de Janeiro State (Brazil). Revista Brasileira de Plantas Medic 15: 438-441.

Rezaeieh, K.A.P., Gürbüz, B. (2017). Volatile oil yield and constituents of Salvia officinalis, S. tomentosa Mill. and S. glutinosa growing in Ankara, Turkey. Asian J of Agric Res 11: 43-47.

Santos-Gomes, Fernandes- Ferreira, M. (2001). Organ- and season-dependent variation in the essential oil composition of Salvia officinalis L. cultivated at two different sites. J Agric Food Chem 49: 2908-2916.

Seçmen Ö., Gemici, Y., Görk, G., Bekat, L., Leblebici, E. (2000). Tohumlu Bitkiler Sistematiği. Ege Üniversitesi, Fen Fakültesi Yayınları Serisi No: 116, İzmir. Şenkal, B.C., İpek, A., Gürbüz, B., Türker,A., Bingöl, M.Ü. (2012). Bolu ekolojik koşullarında yetiştirilen Salvia officinalis L. ve Salvia tomentosa L. türlerinin baz1 önemli tarımsal özelliklerinin belirlenmesi. Tarım Bili Araş Der 5: 3842.

Topuz, E., Madanlar, N. (2006). Bitkisel kökenli eterik yağlar ve zararlılara karş1 kullanım olanakları. Derim 23: 54-66.

Tuğlu, Ü., Baydar, H. (2019). Tıbbi adaçayı (Salvia officinalis L.)'nda klon seleksiyonu ile geliştirilmiş b-klonlarının tarımsal ve teknolojik özellikleri. Süleyman Demirel Üniv Fen Bilim Enst Der 23: 452-456.

Yenikalayc1, A. (1998). Çukurova bölgesinde doğal adaçayı türleri (Salvia ssp.) ile tıbbi adaçayı (Salvia officinalis L.)'nın kültürü ve kemotaksonomik araştırmalar. Doktora Tezi. Cukurova Üniversitesi Fen Bilimleri Enstitüsü Tarla Bitkileri Anabilim Dalı, $153 \mathrm{~s}$.

Yılmaz, H. (1988). Tıbbi adaçayı (Salvia officinalis L.)'nda ekolojik ve morfogenetik varyabilite. Yüksek Lisans Tezi, Çukurova Üniversitesi Fen Bilimleri Enstitüsü Tarla Bitkileri Anabilim Dal1, 35s.

Zutic, I., Putievsky, E., Dudai N. (2003). Influence of harvest dynamics and cut height on yield components of sage (Salvia officinalis L). J of Herbs, Spices and Medic Plants 10: 49-61. 